\title{
Application of expert systems in diagnostics, management and logistics
}

\author{
Zbigniew Korczewski, Assoc. Prof. \\ Polish Naval University
}

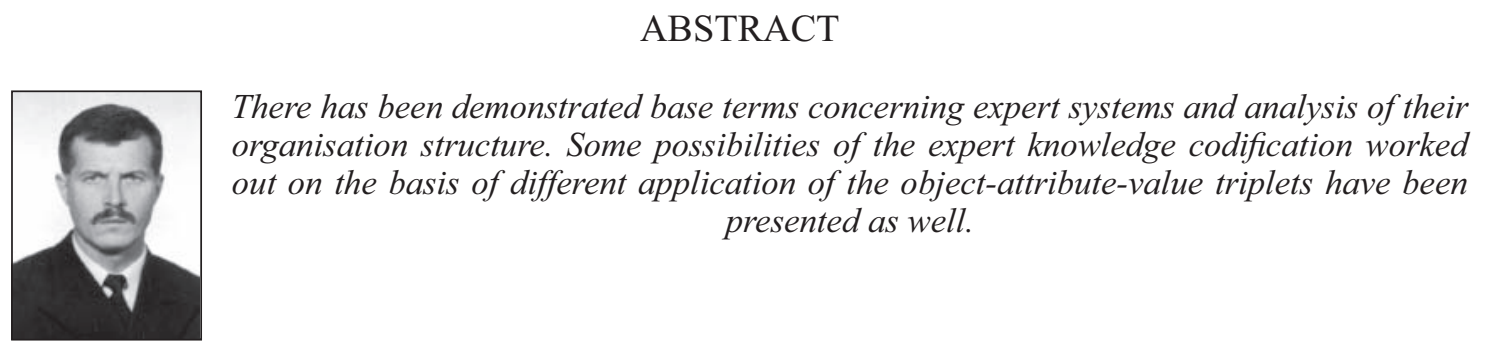

Keywords: diagnostics, expert systems, logistics, management, power plants, simulate human behaviour

\section{INTRODUCTION}

Since the Second World War was finished the British and American research workers who dealt with computer technique have tried to develop research methods which would enable the computers to simulate human behaviour. As a result of such activities a new interdisciplined science domain arised. Nowadays the domain is called artificial intelligence. Within the artificial intelligence expert systems develop in especially dynamical way. They are viewed as intelligent computer programmes that are able to solve complex medical, technical, economic and organisation problems by means of proper usage of available utility knowledge $[3,4,5,8]$. The solved problems usually need significant human expertise. From such a point of view a generated expert model belonging to the best practitioners as well as implemented infer procedures represent a necessary knowledge to perform an ordered decision task.

Contemporary expert systems posses a lot of merits thanks to which they may supplement perfectly action of ,alive” expert. They might be even more reliable in some circumstances. It results from imperfection of human being that characterises:

$\star$ tendency, lack of consequence and flexibility in estimation of real situations

$\star$ lengthened reaction time on quick changeable events and facts

$\star$ difficulties in formulating logical conclusions in case of uncertain and incomplete information

* frequent weariness, insufficient concentration, limited possibilities in reminding themselves a big number of date, that are deepened in difficult, stressful situations.

Additionally, growing popularity of the expert systems results from organisation regards and as a consequence imperfection of the reality surrounded us:
+ personnel rotation within expert cluster

+ high service charges, the higher expert class and complex (expensive) diagnose object the higher service charges are

+ limited possibilities of transporting "alive" experts.

\section{ORGANISATION STRUCTURE OF AN EXPERT SYSTEM}

The expert knowledge represents the base of the organisation structure of each expert system [1]. The knowledge consists of following elements:

$\Rightarrow$ facts - standing for information matter of an expert object that is commonly available and arranged by the expert of the considered domain

$\Rightarrow$ heuristics (rules) - being in the majority of cases personal, in some circumstances subjective and discussible rules of proper interpretation of the possessed facts. The facts are consequently adjusted according to probable, possible to acceptation reasoning and characterise decision taken by the expert in the determined detail level depending, of course, on the extent of the knowledge possessed.

For instance, technical state evaluation of a device by means of an expert system application is carried out by the particular way i.e. mainly on the basis of characterising symptoms occurred during its improper running, observed by the user. The system gathers the knowledge about a technical shape of the device by means of inquiring the user (directly). The answers are selected in an operating memory of the system $[4,6,7]$. The knowledge depends on subjective, often suggestive estimation done by the user who must carefully stare at and listen to the device's running before starting work with computer-expert. That is why the knowledge is sometimes "washed away" and even uncertain. 
The user should be also able to answer the questions asked by the computer program at once.

Computer - expert taking into consideration appropriate confidence factor (CF), formulates diagnosis. Its correctness depends on information incorporated into the knowledge base. The base represents a main junction of the expert system, besides deduction mechanism-Fig. 1. An operating memory is coupled to the knowledge base. It contains current information about the expertised object, obtained from the consultations

Some subsystems are coupled to the deduction mechanism:

$>$ knowledge acquisition

$>$ explanations

user's interface.

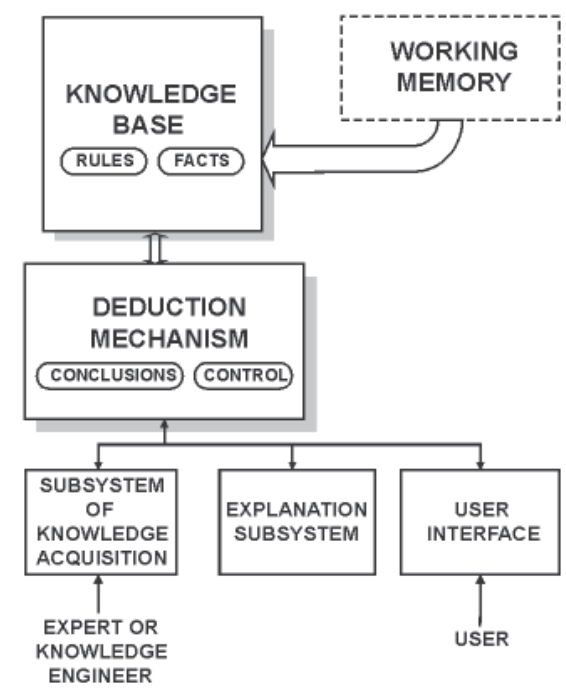

Fig. 1. Organisation structure of an expert system

The deduction mechanism contains deduction strategy and controllers the expert used while manipulating with facts and rules.

The problem of knowledge representation consists in finding such a method of figurative expert knowledge codification which reflects precisely what the expert knows and subsequently - transforming the knowledge into computer language. The specialists constructing the expert systems (having the knowledge base as a ground) deal with foregoing problem. The main task of the computer, that is viewed as the system device relies on efficient manipulating with this knowledge.

Building the semantic networks represents the most frequent method of an expert knowledge representation. Deduction rules are the main link of the networks. They have following form: where:

„If CONDITION, then CONCLUSION.'”

is CONDITIONS - define a determined requirement (requirements) that must be fulfilled in order to apply the given rule

is CONCLUSIONS - determine statement (statements) or activities, that should be done in case while the condition has been fulfilled.

Expert's diagnostic activities are very often connected with (because of various reasons) illogical, imprecision observations and data or even their lack, moreover the gathered information (from expert interviews) are often subjective and difficult to univocal interpretation $[1,2]$. Thus the sensible deduction mechanism should be equipped with confidence factors defining a level of correctness for each deduction rule. They are assigned to the conditions as well as the conclusions within deduction rules, implying scopes of their permissible values and connected with them, a probability of the existence within the scopes. The confidence factor defines accordingly, that is to say, the boundary conditions, that univocally determine what value of the confidence factor is able to activate the determined deduction rule. According to the most common, familiar approach towards the deduction issue there is a classic, double value Boole's algebra [2], where only two value of the confidence factor is distinguished:

$\mathrm{CF}=0$ ("NO"), it means - false

$\mathrm{CF}=1$ ("YES"), it means - true.

Widening the deduction mechanism by i.e. "washes away" reasoning there is distinguished fractional values of the confidence factor given from the scope between 0 and 1 or from the scope between -100 and $+100[3,4]$. The confidence factor represents, in this case, probability of choice (expertise) existence on condition that the particular attributes of the expertise object take determined values. They are defined by means of the probability $p_{b k}$ within the successive deduction rules, $n$. The confidence factor may be determined from the following formulas:

- as an average value of the probabilities:

$$
\mathrm{CF}=\frac{\sum_{\mathrm{k}=1}^{\mathrm{n}} \mathrm{p}_{\mathrm{bk}}}{\mathrm{n}}
$$

- as dependent probabilities:

$$
\mathrm{CF}=\bigcap_{\mathrm{k}=1}^{\mathrm{n}} \mathrm{p}_{\mathrm{bk}}
$$

- as independent probabilities:

$$
\mathrm{CF}=1-\left(1-\mathrm{p}_{\mathrm{b} 1}\right)\left(1-\mathrm{p}_{\mathrm{b} 2}\right)\left(1-\mathrm{p}_{\mathrm{b} 3}\right) \ldots\left(1-\mathrm{p}_{\mathrm{bk}}\right)
$$

\section{OBJECT - ATTRIBUTE - VALUE RELATIONS}

The most common way of writing the expert system knowledge is fact's representation by means of OBJECTATTRIBUTE-VALUE relations. Within such a notation the particular ATTRIBUTES (features) having particular values are assigned to the OBJECT. The OBJECT may be viewed as a physical unite (concrete, thing), like: human being, technical device or a notion unit, like: a fact of device's purchase as well as a selection of the company manager. In general the ATTRIBUTES are characteristics or features connected with the OBJECT. Dimensions or physical chemistry features stand for typical ATTRIBUTES to the physical OBJECTS. For instance, the purchase price or income tax (VAT) may be the ATTRIBUTE for an events of the device purchase. The OBJECT-ATTRIBUTE constraint is a "have" type.

A VALUE that defines precisely a character or nature of the ATTRIBUTE during especial situation of the evaluation process, represents particular, the last one element of the characteristic triple of the expert knowledge notation. The ATTRIBUTE-VALUE constraint is a "be" type. For instance, a human high may be "tall" or an income tax of the purchase price may amounts " $7 \%$ ".

In the Fig. 2 we can see an example of the facts representation for expert system by using OBJECT-ATTRIBUTE-VALUE relations. In the analysed case, a flow path of a gas turbine engine stands for the OBJECT. A technical state of flow passages is one of the flow path's ATTRIBUTES. It is possible to attribute VALUE "fouling" to the "technical state of flow passages". 


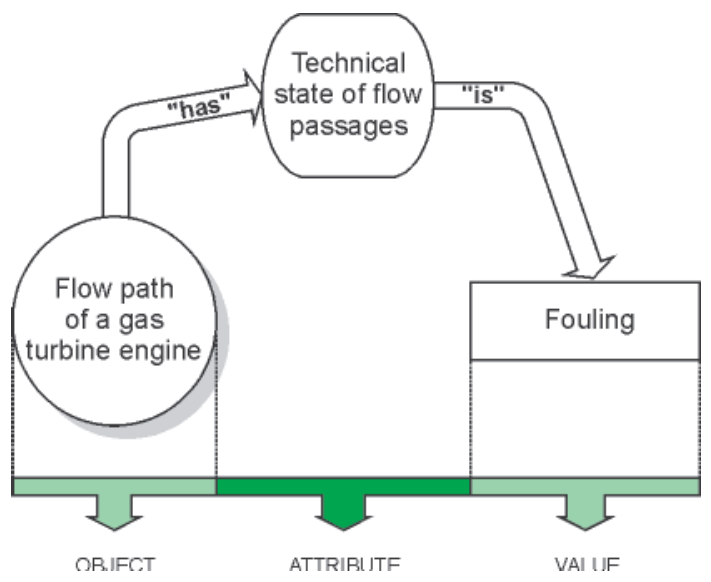

Fig. 2. Object-attribute-value relation

\section{Diagnostic applications}

\section{Engineering}

Expert systems are very useful, commonly applied diagnostic ,tools" for assessing the operation shape of complex technical objects. A necessary expert knowledge is gathered in the form of "failure-symptom" correlations incorporated as a result of:

$\square$ experimental examinations carried out on the real objects,

\. simulation experiments carried out on computer programmes which are especially built for this purpose (if there is no possibilities to examine a real object) $[4,6,7]$.

An example of object-attribute-value relation applied within diagnostic evaluation is presented in Fig. 3. The diagnostic evaluations concerns a compressors unit of the naval gas turbine. Diagnosing process relies on the analysis of thermogasdynamic parameters of the air flow along the considered unit. The parameters' alterations are observed during the engine's unsteady processes: acceleration and deceleration of the engine shafts.

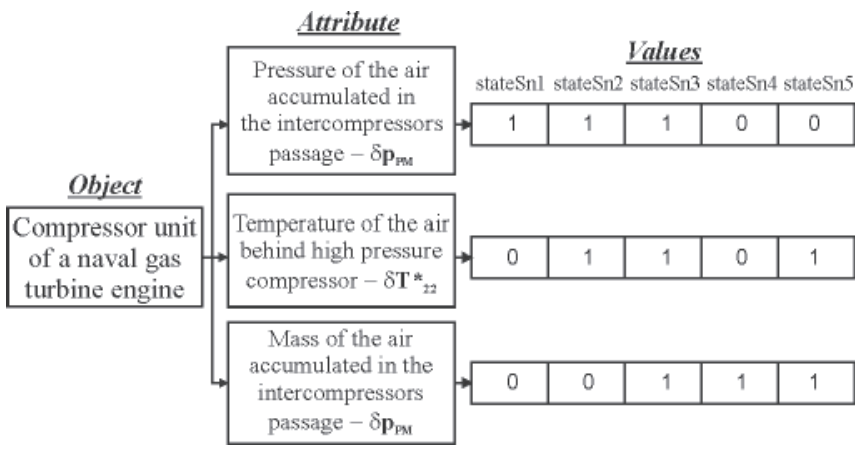

Fig. 3. Object-attribute-value relations within the expert system for diagnostic purposes of the compressors unit of a naval gas turbine engine: , 1 " - diagnostic parameter $\delta x j$ reacts to the unserviceability state Sni by $10 \%$ exceedance of the tolerance field limits, , 0 " - diagnostic parameter does not react to the unserviceability state.

The presented relations results from the simulation experiments worked out on the adequate mathematic model. The following unserviceability operation states of the analysed compressor unit were introduced into the simulation model [7]:

Sn1 - fouling the low pressure compressor's flow passages

$\mathrm{Sn} 2$ - the simultaneous intensive fouling the inter-blade passages of both the compressors mating in series

Sn3 - the air leakage from the intercompressor passage
Sn4 - the leakage of one out of two air bleeder valves behind high pressure compressor

Sn5 - the defect of the automatic fuel supply system of the engine, resulting in engine acceleration process (it was assumed that the time of the air pressure increase behind the high pressure compressor shortened).

Measurable symptoms of the technical state alterations that put up maximum quantity of gained information about simulated unserviceability states represent the object's attributes [7]. It is relevant from the data in figure 3 that the observed values of the respective diagnostic parameters enables performing a univocal identification of considered failures of the compressors unit.

\section{Medicine}

Diagnosing optic nerve illnesses as well as illnesses of subsequent sections of the optic way represent vulnerable area for an expert system implementation. While the optic nerve is damaged the significant handicap of sight eye or even total blindness of the particular eye may occur. Such disturbances result, among the others, from trauma, optic nerve, inflammation, ishaemia, tumour press or because of atrophy. This is possible to localise focuses that damage the optic way. It may be achieved on the basis of analysing anatomic data of the optic way and disturbances within visual field correlated to the optic way. Precise examinations of a visual field are carried out by means of computer perimeter [9]. Every one of registered lack of display legibility within visual field correspond to particular localisation of damage's focus. Possible cases of disturbances within visual field have been presented in Fig. 4.

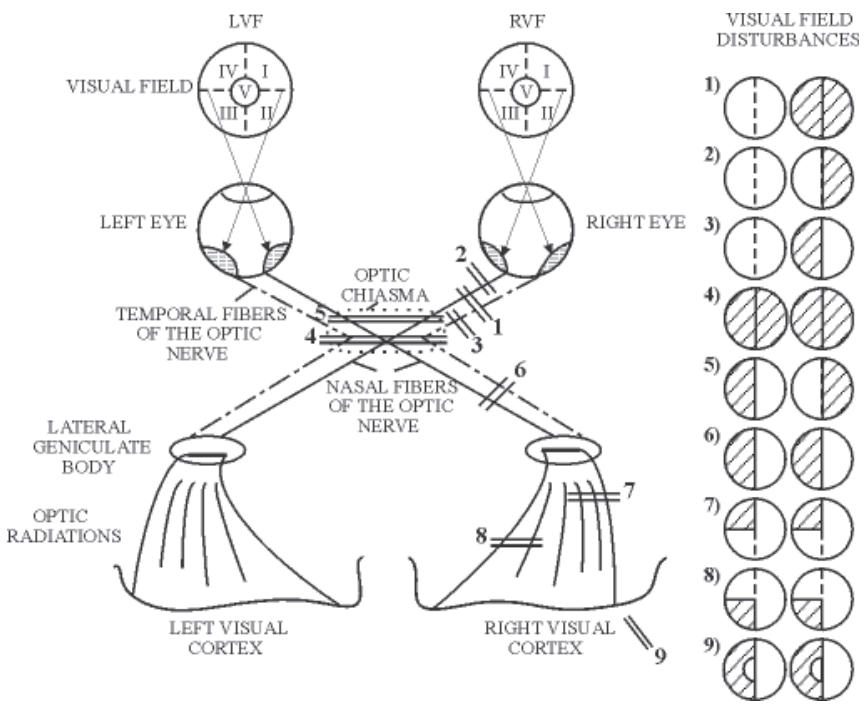

Fig. 4. Visual field disturbances. I, II, III, IV, $\boldsymbol{V}$-sections of visual field, $L V F, R V F$ - respectively: left and right visual field, 1 - right eye ipsilateral blindness, 2 - loss of temporal (external) part of the right eye visual field, 3 - loss of nasal (internal) part of the right eye visual field, 4 - total blindness, 5 - bitemporal hemianopsia, $\mathbf{6}$ - left hemianopsia, 7 - left superiol quadrantanopsia, 8 - left inferiol quadrantanopsia, 9 - homonymous hemianopsia with macula saved

Arab numerals denote possible places where optic way's damages may occur and responding to them disturbances of the visual fields:

Example 1. Entire damage of the optic nerve of the right eye before the optic chiasma gives right eye ipsilateral blindness.

Example 2. Partial, medial damage of the right optic nerve gives loss of temporal (external) part of the right eye visual field. 
Example 3. Partial, external damage of the right optic nerve gives loss of nasal (internal) part of the right eye visual field.

Example 4. Entire damage of the optic chiasma gives total blindness.

Example 5. Partial, medial damage of the optic chiasma gives bitemporal hemianopsia.

Example 6. Entire damage of the right optic nerve behind the optic chiasma gives left hemianopsia.

Example 7. Partial, external damage of the right optic radiations gives left superiol quadrantanopsia.

Example 8. Partial, medial damage of the right optic radiations gives left inferiol quadrantanopsia.

Example 9. Partial damage of the right optic cortex causes homonymous hemianopsia with macula saved. There is possible that the quadrantanopsia may also appear among damages of the optic cortex.

In order to improve diagnostic inferring process concerning physiopathological state of the optic nerve, that bases on a digital notation registered by computer perimeter, it should be firstly defined an adequate set of object-attribute-value expert relation within neurological knowledge that is supported by appropriate results of clinical examinations.

In Fig. 5 there has been proposed the simplest 0-1 (Boole's algebra) approach to the codification of the estimation relations with reference to considered cases of visual field disturbances. It is relevant from the numerical data ascribed to the particular attributes of the examined object that it is possible to define synonymously the state of optic nerve physiopathology. For instance, it can be concluded, when analysing the set of the diagnostic parameters, that a right eye ipsilateral blindness (Sfp1 physiopathological state) happens, if the result of $\{0000011111\}$ appears during the diagnostic investigation. No identical result appears elsewhere.
It is worth pointing out that disturbances within visual field shown in Fig. 4 represent a significant simplification and occur rarely in so typical manner. In daily experience we usually deal with lacks in visual field that are much more varied, less regular, difficult repeatedly to univocal interpretation. In such a situation result (display) of clinical examination might be characterised by "washes away" values of optic nerve's attributes. As a consequence one test result may correspond to several focuses damaging the optic way.

\section{Managing applications}

Very often in our profession there is a necessity to evolve the best candidate for managing position between the company workers. In all the cases this is a very complex and responsible managing task that decides about a father development of the determined organisation cell. Getting to the realisation of the task there should be considered following organisation issues with many-sided way:

$\diamond$ How to define vital criteria (attributes) for estimation of personal-professional features of the intended manager of an organisation cell?

$\diamond$ Which personal values (rational and irrational) should be assigned to the respective candidates?

$\diamond$ Which one out of destined features are especially vital and which one have less meaning?

In order to obtain proper answers for such a way formulated questions (and similar) there should be performed multirepeated simulation experiments on possible selections of the candidate that are worked out by means of the expert system.

In the first stage of an estimation process there should be properly written a knowledge of the company expertmanager The knowledge should be written in the form of object-attribute-value relations. In Fig. 6 there has been

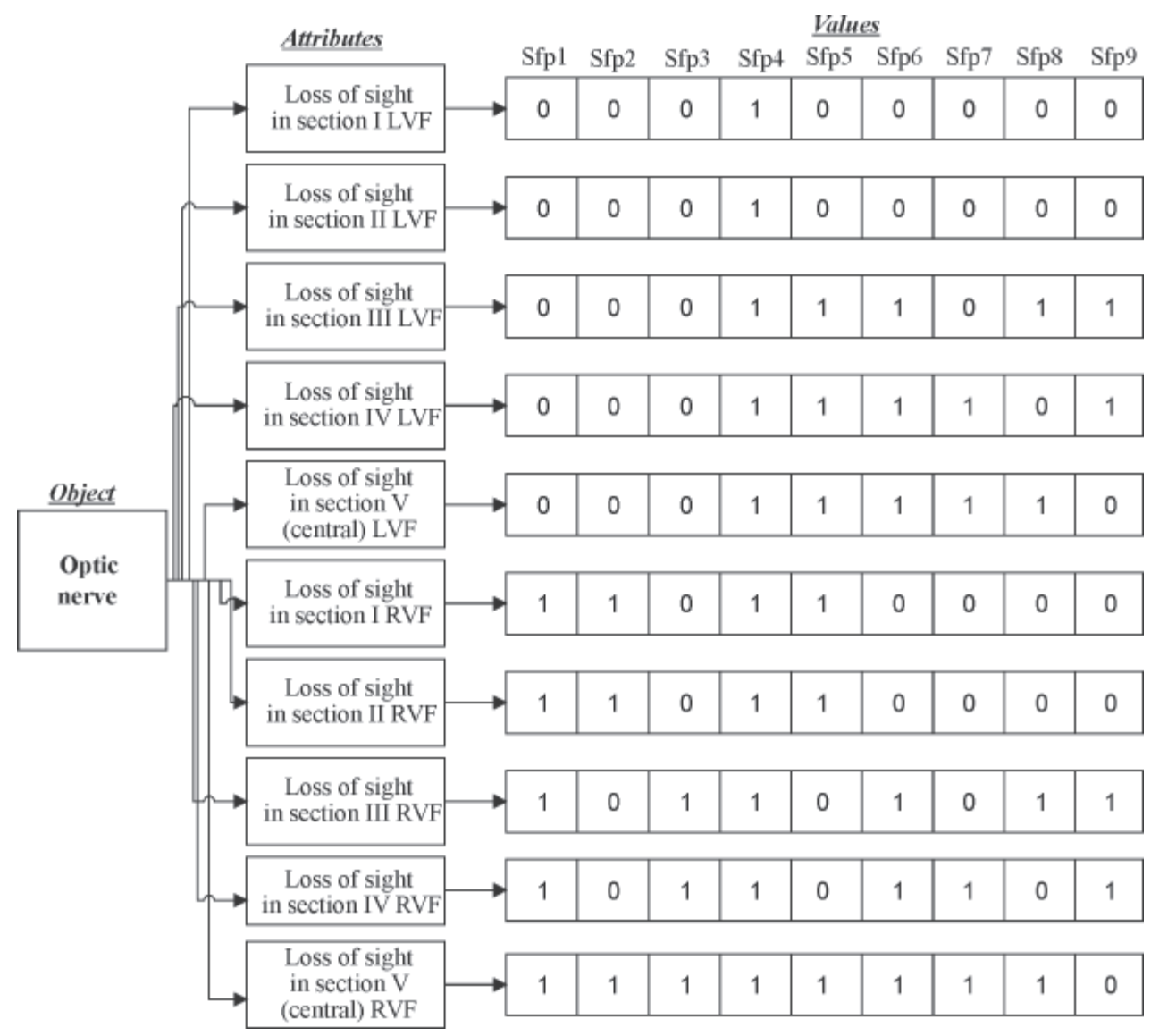

Fig. 5. Object-attribute-value relations within the expert system for estimation of optic nerve physiopathological state Sfp1,...Sfp 9 - successive optic nerve physiopathological state - known and recognisable cases of visual field disturbances „, 1 ”- registered (computer perimeter) loss of sight, ,, 0 ” - correct sight 
demonstrated an example of such a notation in relation to maritime university.

Perennial organisation experiences encountered from maritime university activity have given possibility to elaborate a wide list of attributes in the considered case of personalprofessional features of the created manager of an organisation cell. They represent a psycho-physical portrait of the intended candidate. The silhouette of the potential manager involves professional qualifications as well marked out personality features that the candidate should possess.

Following values have been assigned to the defined attributes:

$\mathrm{ZPwW}$ - much more above requirements - the range of suitability coefficient: $(+90) \div(+100)$,

$\mathrm{PwW}$ - above requirements - the range of suitability coefficient: $(+70) \div(+90)$,

SW - fulfils requirements - the range of suitability coefficient: $(0) \div(+70)$,

$\mathrm{PnW}$ - below requirements - the range of suitability coefficient: $(0) \div(-70)$,
ZPnW - much more below requirements - the range of suitability coefficient: $(-70) \div(-90)$,

NSW - does not fulfil requirements - the range of suitability coefficient: $(-90) \div(-100)$.

Four candidate have been subjected to the estimation procedure. They have been maritime university lectures. Respective values of the attributes, that influence the worked out professional duties have been assigned to the candidates. The main aim of the expert system consists in carrying out the estimation of the competence for each one candidate and pointing out which candidate is the best choice for the future manager

\section{Logistics applications}

An adequately created expert system is able to support the choice and purchase processes concerning different products. The heart of its usage consists in estimation: which one from considered objects is the most suitable to the user's needs. In order to work out such a formulated expert task there should

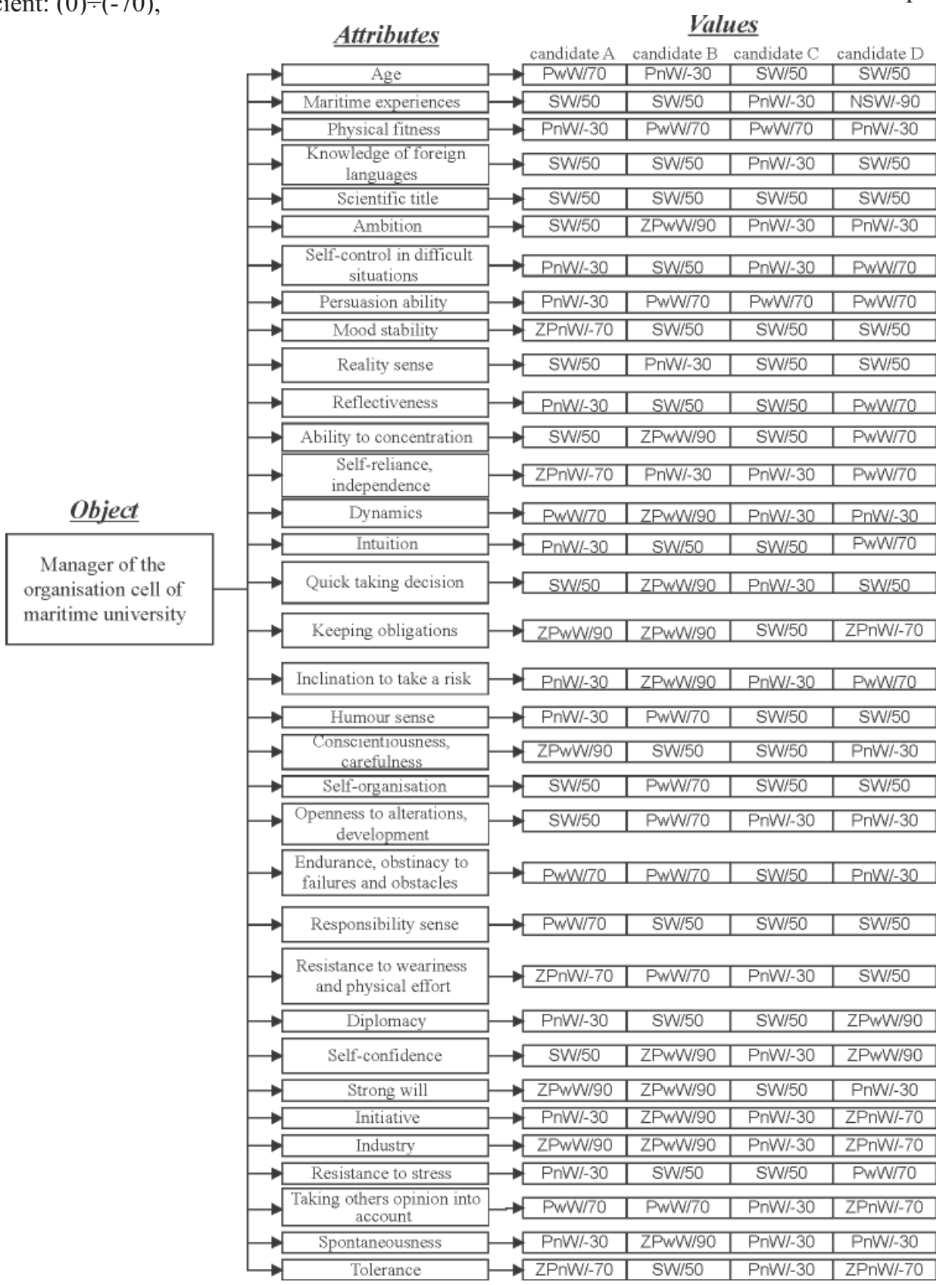

Fig. 6. Object-attribute-value relations within the expert system for estimation of personal-professional features for the selection purpose of the competent manager of an organisation cell of an organisation cell. Company manager decides personally about desirable values of the personal-professional features that potential candidate should possess 


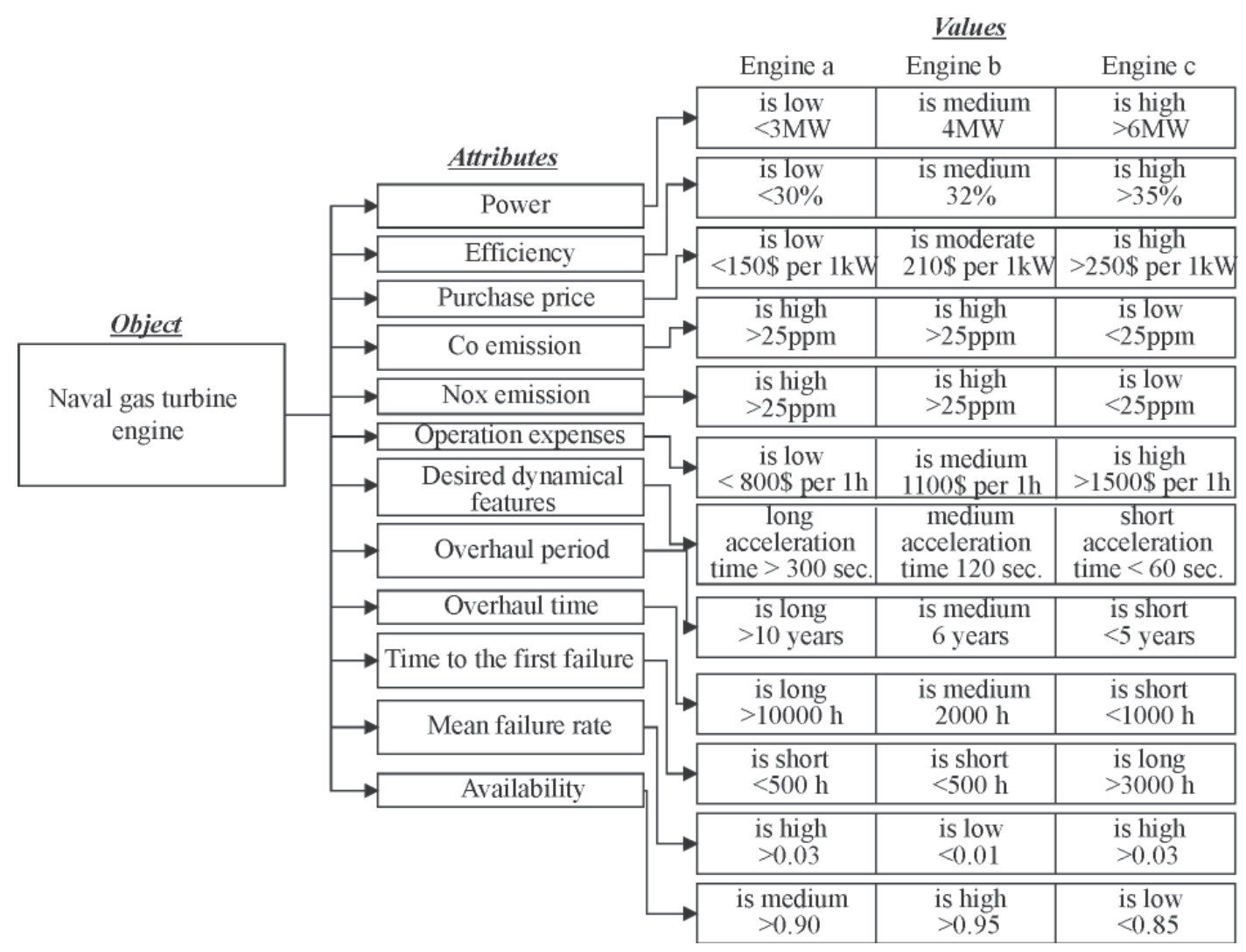

Fig. 7. Object-attribute-value relations within the expert system for choice and purchase a gas turbine engine of the vessel's propulsion

be precisely definited the estimation criteria, and consequently respective measures and values should be assigned to the established criteria.

In marine practise there are often taken decisions concerning a selection of the „most appropriate" type of the main engine for propelling propulsion system. In all the cases the issue needs carrying out universal techno-economical analysis within the world engine market. The performed analysis should be supported with penetrating estimation of the geopolitical situation of the producer's country.

As a result the list of familiar units is coming into existence. It helps to restrict a quantity of the products taken into consideration. We usually dispose several or even more types of propelled engines. Their usefulness for the application is determined with the values of the earlier defined estimation magnitudes. In Fig. 7 there has been demonstrated a trial of the expertise expression of such a task. The expert knowledge is written down by means of object-attribute-value relations. Within considered case the solved problem consists in selection of naval gas turbine engine destined as a cruise engine in twinshaft COGAG propulsion system.

The attributes of the purchased object represent technical parameters of the estimated engines as well as general purchase and operation expenses. Within demonstrated case there have been only taken into consideration fundamental estimation magnitudes. Their values results from subjective Author's opinion and thus their are controversial and left for Readers to think their over.

\section{CONCLUSIONS}

For last several years there has been observed a tendency to more and more interest of the human being with possibilities that a development of the wide-understood computerisation puts up. Expert systems develop stormily confirming their high usefulness to solve complex decision problems. They are created on the base of more and more perfect computer hardware. The examples of writing the expert system knowledge in the form of object-attribute-value relation shown within the paper demonstrate only a piece of possible applications. They represent for the Author an introduction for further works concerning different way of formulating the conclusion rules, as a base link for every expert system.

\section{BIBLIOGRAPHY}

1. Bolc L., Cytowski J.: Metody przeszukiwania heurestycznego. PWN, Warszawa 1989.

2. Bolc L., Borodziewicz W., Wójcik M.: Podstawy przetwarzania informacji niepewnej i niepetnej. PWN, Warszawa 1991.

3. Chadwick M., Hannah J.: Expert systems for microcomputers. An introduction to artificial intelligence. TAB BOOKS Inc., USA 1996.

4. Cholewa W., Pedrycz W.: Systemy doradcze. Skrypt Politechniki Śląskiej, Gliwice 1987.

5. Harmon P., King D.: Expert systems. Artificial Intelligence in Business. A Wiley Press Book, New York USA 1985.

6. Kiciński J.: Systemy komputerowe w budowie i eksploatacji maszyn - stan i perspektywy rozwoju. XXVII Ogólnopolskie Sympozjum „Diagnostyka Maszyn”, Wegierska Górka 2000.

7. Korczewski Z.: Identyfikacja procesów gazodynamicznych w zespole sprężarkowym okrętowego turbinowego silnika spalinowego dla potrzeb diagnostyki. Wydawnictwo monograficzne. AMW Gdynia 1999.

8. Mulawka J.: Systemy ekspertowe. WNT Warszawa 1996.

9. Prusiński A.: Podstawy neurologii klinicznej. PZWL Warszawa 1989.

CONTACT WITH THE AUTHOR

Assoc. Prof. Zbigniew Korczewski

Mechanic-Electric Faculty, Polish Naval University Śmidowicza 69

81-103 Gdynia POLAND e-mail: zkorczewski@wp.pl 